\title{
BMJ Open Factors influencing medical students' motivation to practise in rural areas in low-income and middle-income countries: a systematic review
}

\author{
Shyam Sundar Budhathoki, ${ }^{1}$ Prisca A C Zwanikken, ${ }^{2}$ Paras K Pokharel, ${ }^{1}$ \\ Albert J Scherpbier ${ }^{3}$
}

To cite: Budhathoki SS, Zwanikken PAC, Pokharel PK, et al. Factors influencing medical students' motivation to practise in rural areas in low-income and middleincome countries: a systematic review. BMJ Open 2017;7:e013501.

doi:10.1136/bmjopen-2016013501

- Prepublication history for this paper is available online. To view these files please visit the journal online (http://dx.doi.org/10.1136/ bmjopen-2016-013501).

Received 18 July 2016 Revised 20 December 2016 Accepted 2 February 2017

CrossMark

\footnotetext{
${ }^{1}$ School of Public Health \& Community Medicine, B P Koirala Institute of Health Sciences, Dharan, Nepal

${ }^{2}$ Royal Tropical Institute, Amsterdam, The Netherlands ${ }^{3}$ Faculty of Health, Medicine and Life Sciences, University of Maastricht, Maastricht, The Netherlands
}

Correspondence to Dr Shyam Sundar Budhathoki; ss.budhathoki@gmail.com

\section{ABSTRACT}

Objectives: There is a shortage of doctors working in rural areas all over the world, especially in low-income and middle-income countries. The choice to practise medicine in a rural area is influenced by many factors. Motivation developed as a medical student is one key determinant of this choice. This study explores influences on medical students' motivation to practise in rural areas of low-income and middle-income countries following graduation.

Design: A systematic review was conducted to identify influences on medical students' motivation to work in rural areas in low-income and middle-income countries. Papers reporting influences on motivation were included, and content analysis was conducted to select the articles. Articles not published in English were excluded from this review.

Results: A rural background (ie, being brought up in a rural area), training in rural areas with a communitybased curriculum, early exposure to the community during medical training and rural location of medical school motivate medical students to work in rural areas. Perceived lack of infrastructure, high workload, poor hospital management and isolation are among the health facility factors that demotivate medical students for medical practice in rural areas.

Conclusions: Medical school selection criteria focusing on a rural background factor and medical education curriculum focusing on rural area are more relevant factors in low-income and middle-income countries. The factors identified in this review may assist the planners, medical educators and policymakers in low-income and middle-income countries in designing relevant interventions to positively influence rural choices where the shortage of rural physicians is an ongoing and increasing concern.

\section{INTRODUCTION}

Approximately half of the world's population resides in rural areas, while $<25 \%$ of physicians provide services to rural communities. ${ }^{1}$ Poor access to health workers impacts more
Strengths and limitations of this study

- This study focuses on the motivating factors among medical students, unlike most studies, which focus on medical doctors and specialists.

- Using a conceptual framework based on a problem tree approach structured the findings and discussion.

- This study is relevant for all low-income and middle-income countries that face challenges in recruiting medical doctors to work in rural areas.

- The inclusion of English language articles only in this review may have resulted in missing some possibly important papers published in other languages.

- The conclusion is based on low-quality evidence only, as studies with moderate and high evidence were not found in the literature search.

than one billion people, ${ }^{1}$ with communities in Africa and Southeast Asia experiencing the most significant disadvantage. ${ }^{2}$ Unequal distribution of healthcare workers between urban and rural areas leads to poorer health among rural people. ${ }^{3} 4$ This in turn affects the health and development-related indicators of the countries. ${ }^{5}$

In a cross-sectional study in 2012, 9 out of 10 students in Nepal intended to work in Nepal after graduation from medical school, but only 1 out of 10 were interested in possibly working in rural areas. ${ }^{6}$ In similar studies since 2010 in other countries, career intentions in rural locations among medical students are reported to be very low in Bangladesh, ${ }^{7}$ sub-Saharan Africa ${ }^{8}$ and South Africa. ${ }^{9}$ Studies from India and Ethiopia show slightly higher rates with about one out of five medical students showing career interest in rural locations after graduation. ${ }^{10} 11$

Decisions made by new doctors about where to establish their careers are influenced by a range of personal, economic, 
familial, cultural and environmental factors. ${ }^{12}$ Medical training, local and national policy, and factors related to the location of the health facility also play a role in career decisions. ${ }^{13}$ Decisions about practice location are made during medical training. ${ }^{14}{ }^{15}$ Experiences during medical school have a powerful influence over many students' choices. ${ }^{16}$

Many determinants contribute to medical graduates' choices relating to career locations. ${ }^{17}$ It is an important and difficult decision for many medical graduates about where to start their career. The choice influences future career choices and opportunities, as well as family and social life. ${ }^{18}$ Understanding what motivates the medical students at the time they are making this choice will assist medical educators, researchers and policymakers to more effectively structure their educational experiences and establish appropriate motivations that encourage more medical graduates to practise in rural settings. ${ }^{19} 20$ The WHO has recommended a set of interventions to increase the access of health workers in rural areas globally. ${ }^{5}$

Relevant reviews can be found regarding the medical students' motivation to work in rural areas of highincome countries. The factors identified in reviews from high-income countries include the rural background of the medical student and the medical school selection criteria to select the students with rural background as motivators for future rural practice. ${ }^{15}{ }^{21-27}$ Rural areas of high-income countries are different from rural areas of low-income and middle-income countries (LMICs) and differ by income groups of countries, yet the motivation for working in rural areas is a challenge faced by all countries.

No review focusing on medical students' motivation to work in rural areas in LMICs was found in a thorough literature search. The current study sought to review the literature to identify factors influencing medical students' motivation to practise in rural areas following graduation.

\section{METHODS}

Study design

A literature review was conducted in PUBMED, COCHRANE library, SCOPUS, EMBASE, ERIC and Google Scholar databases in 2016 by two independent researchers.

\section{Conceptual framework}

The Bland model, ${ }^{28}$ illustrating the student characteristics and school characteristics that influence the choice of medical specialty, was used as a reference to prepare a problem tree, which was used to develop a conceptual framework for content analysis, where motivation among the students is a dependent variable influenced by these factors. Individual, work, social and environmental factors interact to influence motivation. These factors guided the construction of the broad

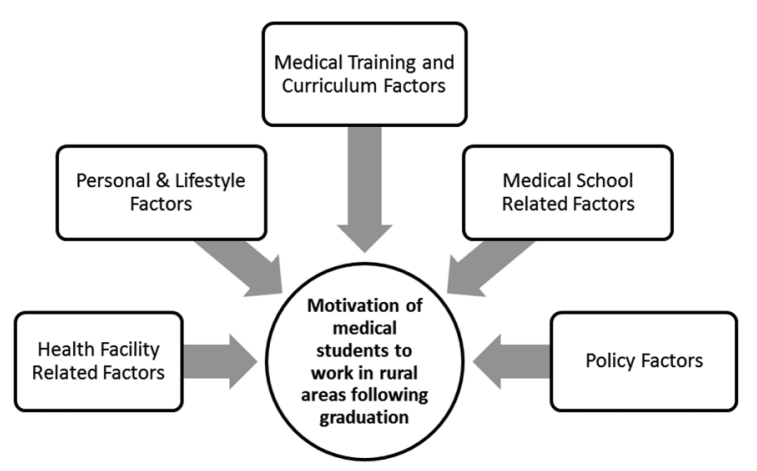

Figure 1 Conceptual framework.

categories of a problem tree for medical students' motivation (figure 1)..$^{29} 30$

\section{Search strategy}

Keywords and Medical Subject Headings (MeSH) were used for each of the three concepts of interest.

Medical students: 'medical students' OR 'undergraduate medical students'.

Motivation: 'motivation' OR 'career choice' OR 'intention'.

Location: 'rural areas' OR 'underserved area' OR 'remote area' OR 'rural practice'.

We used the search strategy (undergraduate medical student) OR (medical student) AND (motivation) OR (career choice) OR (intention) AND (rural area) OR (remote area) OR (Rural practice) for PubMed search.

\section{Inclusion and exclusion criteria}

The inclusion criteria were set to include all articles that were published between 2000 and July 2016 in peerreviewed journals and reported factors influencing medical students' motivation to work in rural areas. Definitions of 'rural area' differ from author to author and from country to country. ${ }^{31-33}$ For this study, the author's use of the terms 'rural area' or 'underserved area' were accepted. Studies reporting practice in LMICs were included. Articles from high-income countries and articles not published in English were excluded.

\section{Outcome measurement}

The outcome of interest in this review is the motivation of medical students to work in rural areas following graduation.

\section{Data extraction}

Following identification of articles from the databases and removal of duplicates, titles and abstracts were screened against the inclusion and exclusion criteria. A content analysis was then undertaken with the papers satisfying the inclusion criteria. Where the review of the full text revealed a paper that did not meet inclusion criteria, it was excluded from further analysis. The title and abstract screening and content analysis were performed by two independent reviewers. The complete article 
selection process is reported using the PRISMA flow chart (figure 2). The PRISMA checklist was used to guide the report writing of the systematic review. ${ }^{34}$ The reported factors influencing medical students to practise in rural areas were extracted using data extraction forms.

\section{Synthesis of results}

Based on the conceptual framework (figure 1), motivational factors extracted from the papers in this review were grouped into five categories: (1) health facility-related factors; (2) personal and lifestyle factors; (3) medical training and curriculum factors; (4) medical school factors; and (5) policy-related factors.

\section{Quality assessment}

The quality of evidence was assessed using the Grading of Recommendations: Assessment, Development and Evaluation (GRADE) approach for observational studies. ${ }^{35}$ The articles in this review were independently assessed for quality by two reviewers and then an agreement was reached on the final quality category.

\section{RESULTS}

The initial database search identified 1862 articles, and following the removal of duplicates and a title and abstract scan, 109 articles were included in the full-text review. A further 96 papers were excluded following a full-text review (24 papers from a high-income countries study and 72 papers not fitting the inclusion criteria).

Thirteen studies were included in this review. The review included eight cross-sectional studies, two qualitative studies, two mixed (qualitative and quantitative) studies and one discrete choice experiment. There were two articles from upper middle-income, three articles from lower middle-income countries, seven articles from low-income countries and one article covering lower middle-income and upper middle-income countries. ${ }^{36}$ The characteristics of the 13 included articles can be found in table 1 .

A summary of the factors influencing the motivation of medical students to work in rural areas after graduation is listed in table 2 .

\section{Health facility-related factors}

Health facility-related motivating factors and impediments to rural practice were found in seven articles. Motivating factors for rural practice included medical students from Uganda expecting that communication with patients in rural areas would be easier, better teamwork, friendly environment. ${ }^{37}$ They also expected that staff would be more supportive ${ }^{38}$ and that there would be more career development opportunities ${ }^{37}$ in rural areas than in urban areas. The students perceived that financial incentives ${ }^{6}$ in Nepal or higher salaries ${ }^{38} 39$ in Botswana and India and provision of good housing ${ }^{39} 40$ in Ghana and India for rural locations acted to motivate
Figure 2 Articles selection process.

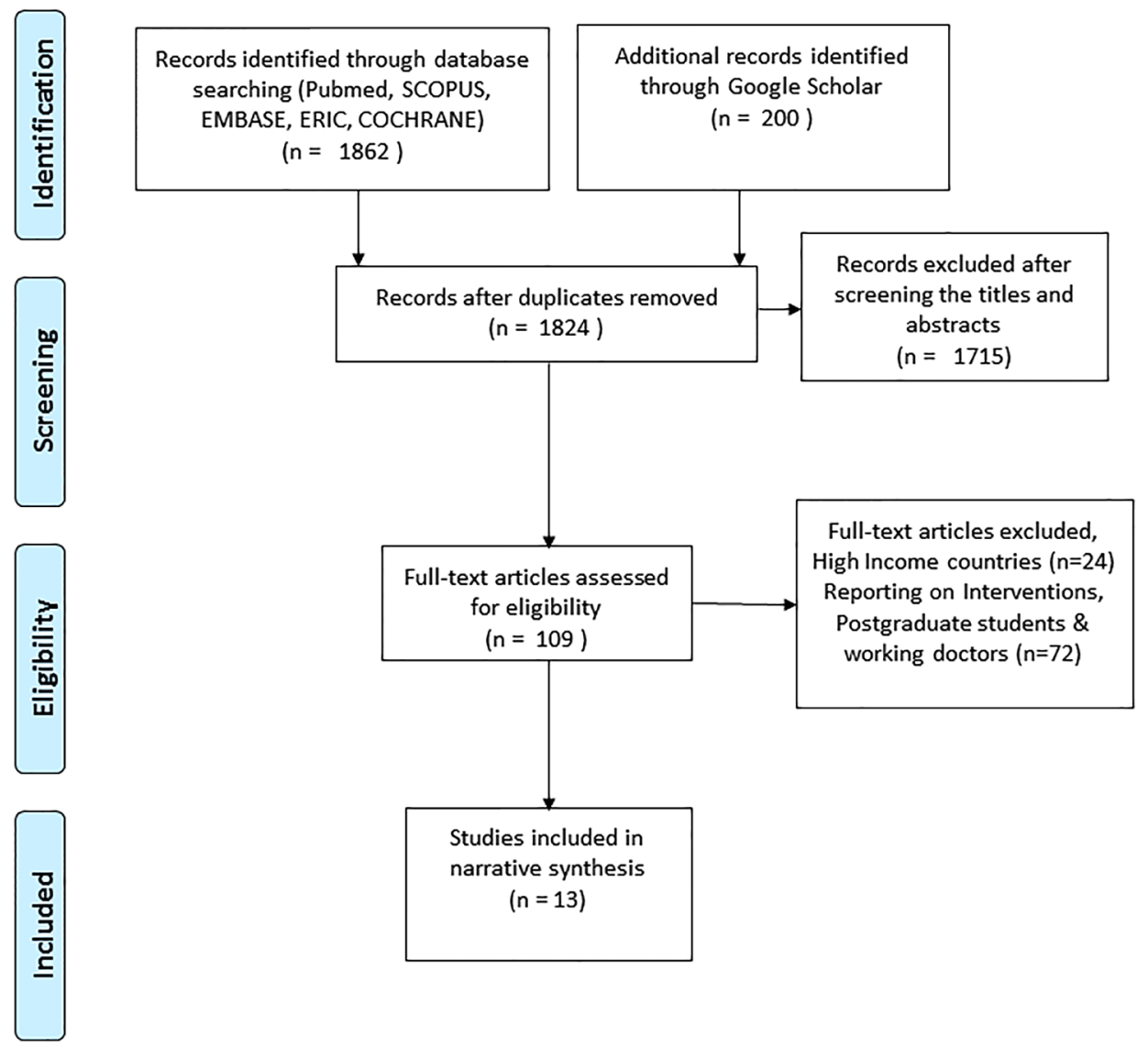


Table 1 Characteristics of articles reporting factors influencing motivation of medical students to work in rural areas following graduation

\begin{tabular}{|c|c|c|c|c|}
\hline Author (year) & Country & Income group of country & Study type & Quality of evidence (35) \\
\hline Arscott-Mills $2016^{38}$ & Botswana & Upper middle income & Mixed methods & Low quality \\
\hline Bailey $2012^{41}$ & Malawi & Low income & Qualitative & Very low quality \\
\hline Deressa $2012^{10}$ & Ethiopia & Low income & Cross-sectional & Low quality \\
\hline Huntington $2012^{6}$ & Nepal & Low income & Cross-sectional & Low quality \\
\hline Kaye $2010^{37}$ & Uganda & Low income & Qualitative & Very low quality \\
\hline Kotha $2012^{45}$ & Ghana & Lower middle income & Cross-sectional & Low quality \\
\hline Kruk $2010^{40}$ & Ghana & Lower middle income & Discrete choice experiment & Low quality \\
\hline Larkins $2015^{46}$ & $\begin{array}{l}\text { Philippines } \\
\text { Sudan } \\
\text { South Africa }\end{array}$ & Lower and upper middle income & Cross-sectional & Low quality \\
\hline Nallala $2015^{39}$ & India & Lower middle income & Cross-sectional & Low quality \\
\hline Ross $2007^{44}$ & South Africa & Upper middle income & Mixed methods & Low quality \\
\hline Shankar $2012^{42}$ & Nepal & Low income & Cross-sectional & Low quality \\
\hline van Wyk $2010^{9}$ & South Africa & Upper middle income & Cross-sectional & Low quality \\
\hline Zimmerman $2012^{43}$ & Nepal & Low income & Cross-sectional & Low quality \\
\hline
\end{tabular}

their decision to work in rural areas. Impediments to rural practice are reported from studies in low-income countries as perceived lack of infrastructure, equipment, supplies and communication facilities within the rural health facility. ${ }^{37-42}$ In Botswana, the expected weak referral system in health and poorly functioning health facility were reported as impediments to future rural practice. ${ }^{38}$ In Malawi, expectations of a high after-hours workload in rural health facilities, trade-off to administrative works over clinical work, lack of opportunities for private practice and high community expectations of physicians were the impediments to practising in rural areas. ${ }^{41}$ Poor hospital management in rural areas was a perceived impediment to rural medical practice among the students in Uganda and Ghana. ${ }^{37}{ }^{40}$ Limited professional development opportunities, ${ }^{38} 3942$ professional career stagnation $^{38}$ and lack of opportunities for higher education and support ${ }^{39} 42$ were perceived as impediments among students for a future career in rural locations in Botswana, India and Nepal. ${ }^{42}$ Rurally located health facilities are considered unsafe during political instability by medical students in Nepal and Uganda. ${ }^{37} 42$

\section{Personal and lifestyle factors}

Personal and lifestyle-related motivating factors and impediments to rural practice were found in 11 articles. Personal and lifestyle motivating factors include findings from Nepal and South Africa, where male students are more likely than female students to practise in rural areas. ${ }^{6} 943{ }^{44}$ Rural background of the student, such as being born in a village, was a motivating factor reported from Botswana and Ethiopia. ${ }^{10} 38$ Completing their elementary school in rural area in Ghana, Nepal, influenced medical students for future rural practice. ${ }^{6} 4345$ Having lived in a rural community was a motivating factor for students to return to rural areas for medical practice in Ghana. ${ }^{37}$ Perceived proximity to family when working in a rural area was a motivating factor for practice in rural areas by students in Botswana. ${ }^{38}$

Students with a paramedical background prior to medical school, completing their high school at an older age and lower grades in medical school were some characteristics found to be linked with working in rural areas of Nepal. ${ }^{43}$ Students perceived diverse work experience as positive motivators for medical practice in rural areas in Botswana. ${ }^{38}$ Medical students from a lower socioeconomic status in Ghana are more motivated to work in rural areas following graduation. The reason for this, according to the author of the study, is due to a greater understanding of poverty that motivates them to help the poor. ${ }^{45}$ In Malawi, medical students' personal values motivate them to serve in rural areas, considering rural service as a part of their duty as a citizen. ${ }^{41}$

Impediments include the needs of the spouse and families for better education for children, perceived to be available in the cities and not rural areas, as reported from Ghana. ${ }^{40}$ The perceived lack of proper housing in a Malawian study, ${ }^{41}$ perceived lack of recreation and entertainment facilities for themselves and the families and the perception of being isolated from friends and family circles in Botswana and Uganda, ${ }^{37} 38$ along with high travel costs associated with travel to and from the rural areas, are impediments to medical practice in rural areas of Ghana and Uganda. ${ }^{37}{ }^{40}$ Students from families with high income were found as a negative predictor for future career location as rural areas in Nepal. ${ }^{6}$

\section{Medical training and curriculum factors}

Medical training and curriculum-related motivating factors and impediments to rural practice were found in two articles. Medical training and curriculum-related factors from a low-income country, Uganda, show that a communitybased medical curriculum motivates and prepares a medical student for future practice in rural areas. These factors include rural posting and training in rural areas. ${ }^{37}$ 
Table 2 Summary of articles reporting factors influencing motivation of medical students to work in rural areas following graduation

\begin{tabular}{|c|c|c|c|}
\hline Author/year & Country & Key findings & Factors \\
\hline $\begin{array}{l}\text { Arscott-Mills } \\
2016^{38}\end{array}$ & Botswana & $\begin{array}{l}\text { Interest to practise in rural areas was expressed by } 9 \% \text { students. } \\
\text { Rural training of medical students was not found to influence preferred future } \\
\text { practice locations rural or urban. } \\
\text { Motivators } \\
\text { Monetary compensation, diversity of practice and supportive staff were } \\
\text { potential motivators. } \\
\text { Medical students with a rural background perceived proximity to their family as } \\
\text { a motivator for rural practice. } \\
\text { Impediments } \\
\text { Impediments to working in rural areas as mentioned by students are perceived } \\
\text { lack of learning opportunities, professional stagnation, isolation, dysfunctional } \\
\text { referral systems, poorly functioning health facilities, lack of recreation and poor } \\
\text { infrastructure in rural areas. }\end{array}$ & $\begin{array}{l}\text { HF } \\
\text { PLS }\end{array}$ \\
\hline Bailey $2012^{41}$ & Malawi & $\begin{array}{l}\text { Postgraduate specialisation is the most important factor for career choice. } \\
\text { Motivators } \\
\text { Motivators for rural practice were to get associated with district people, see } \\
\text { cases that do not reach central hospitals, to work for the people from home } \\
\text { district, to get management skills of administration of hospital and performing } \\
\text { duty as a loyal citizen to the community. } \\
\text { Impediments } \\
\text { Impediments to rural practice were: huge workload, high expectation from the } \\
\text { community, trade-off to administrative work over clinical work, lack of } \\
\text { resources, lack of proper housing, poor living conditions, and lack of good } \\
\text { opportunities for private practice, lack of equipments and lack of good schools } \\
\text { for the children. }\end{array}$ & $\begin{array}{l}\text { HF } \\
\text { PLS }\end{array}$ \\
\hline Deressa $2012^{10}$ & Ethiopia & $\begin{array}{l}\text { Thirty per cent of students expressed interest to practise medicine in rural } \\
\text { areas. } \\
\text { Motivators } \\
\text { Students from a rural background had better odds of medical practice in rural } \\
\text { areas. }\end{array}$ & PLS \\
\hline $\begin{array}{l}\text { Huntington } \\
2012^{6}\end{array}$ & Nepal & $\begin{array}{l}\text { Twelve per cent of the medical students intended to work in rural areas. } \\
\text { Motivators } \\
\text { Male students, government secondary school graduates before joining medical } \\
\text { school, born in a village, sense of duty to the country and financial incentives } \\
\text { for rural careers and scholarship for medical schooling from government were } \\
\text { associated with career intentions at a rural place. } \\
\text { Impediments } \\
\text { High-income family, self-paying private medical school students and feeling of } \\
\text { isolation were associated with no intentions of working at rural areas. }\end{array}$ & $\begin{array}{l}\text { HF } \\
\text { PLS } \\
\text { MS } \\
P\end{array}$ \\
\hline Kaye $2010^{37}$ & Uganda & $\begin{array}{l}\text { Medical students have limited exposure to health facilities in the rural areas. } \\
\text { Motivators } \\
\text { Prior exposure to the community, community-based education, role of family } \\
\text { and friends, career development opportunities, teamwork and friendly } \\
\text { environment of co-workers are positive motivators for career choice in rural } \\
\text { areas. } \\
\text { Impediments } \\
\text { Sense of personal safety, workload, communication, transport, family, } \\
\text { language, ease of communication with patients, cost of living, benefits, local } \\
\text { people culture, opportunity for recreation, school for children, possibility of extra } \\
\text { income, equipment, facility infrastructure and continuing education facilities. } \\
\text { Serious impediments for rural factors were insufficient salary, high workload } \\
\text { with understaffing, poor hospital management, poor accommodation, lack of } \\
\text { equipment, isolation from friends, lack of entertainment and inadequate } \\
\text { opportunities for continuing professional development. }\end{array}$ & $\begin{array}{l}\text { HF } \\
\text { PLS } \\
\text { MTC }\end{array}$ \\
\hline
\end{tabular}


Table 2 Continued

\begin{tabular}{|c|c|c|c|}
\hline Author/year & Country & Key findings & Factors \\
\hline Kotha $2012^{45}$ & Ghana & $\begin{array}{l}\text { Fifty-seven per cent of students are willing to work in rural areas. } \\
\text { Motivators } \\
\text { Rural practice willingness was seen among men, those who completed high } \\
\text { school in rural area, rural living experience and lower socioeconomic class } \\
\text { medical students. }\end{array}$ & PLS \\
\hline Kruk $2010^{40}$ & Ghana & $\begin{array}{l}\text { Motivators } \\
\text { Job preference in rural area was strongly associated with improving the } \\
\text { equipment and supportive management. } \\
\text { Other factors: shorter contracts, increment in salaries, facilities for children } \\
\text { education, transport utility and improving housing were also influential. } \\
\text { - Men were more influenced by improved housing while women were more } \\
\text { influenced by supportive management. }\end{array}$ & $\begin{array}{l}\text { HF } \\
\text { PLS }\end{array}$ \\
\hline Larkins $2015^{46}$ & $\begin{array}{l}\text { Philippines } \\
\text { Sudan } \\
\text { South Africa }\end{array}$ & $\begin{array}{l}\text { Interest to work with the rural and remote population was expressed by } 65.9 \% \\
\text { of students in the Philippines, } 33.5 \% \text { of students in Sudan and } 62.8 \% \text { of } \\
\text { students in South Africa. } \\
\text { Motivators } \\
\text { - Medical school selection criteria to select students with prior education in rural } \\
\text { area expressed intention to serve in rural areas after graduation. }\end{array}$ & MS \\
\hline Nallala $2015^{39}$ & India & $\begin{array}{l}\text { Willingness to work in rural areas was expressed by } 17 \% \text { of government } \\
\text { medical school and } 9 \% \text { of private medical school students. } \\
\text { Motivators } \\
\text { foood housing, high salaries and adequate infrastructure are perceived as } \\
\text { factors that attract medical students towards future rural service. } \\
\text { Impediments } \\
\text { Lack of professional career growth opportunities and opportunities for higher } \\
\text { education in rural location are potential impediments towards rural practice. }\end{array}$ & $\begin{array}{l}\text { HF } \\
\text { PLS }\end{array}$ \\
\hline Ross $2007^{44}$ & South Africa & $\begin{array}{l}\text { Motivators } \\
\text { Students from a rural background return to practise in rural areas. }\end{array}$ & PLS \\
\hline Shankar $2012^{42}$ & Nepal & $\begin{array}{l}\text { High tuition fees at medical school influences the career location choice of the } \\
\text { student. } \\
\text { Motivators } \\
\text { Spending more learning in rural area, training in resource-constraint settings } \\
\text { could motivate the students. } \\
\text { Impediments } \\
\text { Students reported a lack of adequate facilities, inadequate salaries, less } \\
\text { security, fewer opportunities for further education, high tuition fees, isolation } \\
\text { from family and less literacy of rural people as impediments to rural practice. }\end{array}$ & $\begin{array}{l}\text { HF } \\
\text { PLS } \\
\text { MTC } \\
\text { MS }\end{array}$ \\
\hline van Wyk $2010^{9}$ & South Africa & $\begin{array}{l}\text { Eight per cent of students intended for rural practice. } \\
\text { Motivators } \\
\text { Impediments } \\
\text { Impents were likely to go in for rural careers. } \\
\text { Students from rural origin were not likely to opt for rural practice. }\end{array}$ & PLS \\
\hline $\begin{array}{l}\text { Zimmerman } \\
2012^{43}\end{array}$ & Nepal & $\begin{array}{l}\text { Twenty-seven per cent of the medical students are working in rural areas after } \\
\text { graduation. } \\
\text { Motivators } \\
\text { Male students, rural background, rural birthplace, attended high school in rural } \\
\text { area, older age at matriculation, prior medical background before medical } \\
\text { school and lower grades in medical school are associated with rural practice in } \\
\text { Nepal. }\end{array}$ & PLS \\
\hline
\end{tabular}

Students in Nepal perceive that training in resourceconstrained settings of rural areas as a medical student prepares them for medical practice in those areas. ${ }^{42}$

\section{Medical school-related factors}

Medical school-related motivating factors and impediments to rural practice were found in three articles.
Medical school selection criteria to select students from a rural background was a positive influence to motivate students to rural practice in the future in the Philippines, South Africa and Sudan. ${ }^{46}$

Medical school-related impediments include high tuition fees paid for education in Nepal which is associated with no interest in working in rural areas. ${ }^{6}{ }^{42}$ 


\section{Policy-related factors}

Policy-related factors are reported in two articles in this review. In Nepal, government scholarship schemes provided to students with a rural background have been reported as a positive factor to influence their motivation. Students who receive these scholarships are obliged to serve in a rural area for a certain number of years. ${ }^{6}$ Shorter contracts in rural areas were also considered as a potential motivator for rural areas by medical students after graduation in Ghana. ${ }^{40}$

\section{DISCUSSION}

The conceptual framework illustrates the influence of each of the five categories of factors on the motivation of the medical students to practise in rural areas after graduation (figure 1). The health facility-related factors (which are generally related to the development of the national health system) identified in this study are acting mostly as impediments for medical students to work in rural areas due to perceived shortcomings in the rural health facilities. Lack of equipment and supplies, lack of peer support, poor hospital management, and added burden of administration and high expectation from the community is perceived to have a very strong discouraging effect among the medical students involved. These are found in studies from all low-income countries and in one out of five studies from middle-income countries.

Rural areas may differ from country to country; however, studies suggest that the rural background of a medical student in any country motivates them to work in the rural area of that country. The choices of the individuals are influenced by the personal circumstances of one's marriage, spouse's choice, family needs and lifestyle choice for living, housing and recreation. The personal factors identified in this review are mostly impediments that drive individuals away from practising in rural areas. Personal experiences and exposure to rural areas is likely to motivate the individual to enjoy rural lifestyles and thus work in rural areas. Perceived friendly environment and perceived better patient relations motivate students towards working in rural areas.

Relevant factors for medical students are the medical training and curriculum factors. Community-based education gives a positive motivation to the student towards rural communities. Rural trainings are expected to bring the student closer to the community. The communitybased education curriculum builds on the personal factor of rural experience, hence motivating medical students to undertake future medical practice in rural areas as mentioned earlier. There is a need for more research in LMICs on how the community-based medical education and rural-based medical training can motivate medical students to further their medical practice in rural areas.

Closely linked to the education and curriculum factor is the medical school factor. Since the medical school plays an important role from selection of the candidates to implementing its curriculum to producing a doctor, the use of appropriate selection criteria is very important. The schools with criteria to select students with a rural background, experience and education could motivate medical students to serve in rural areas after graduation. The criterion ensuring inclusion of underserved communities is seen as a potential solution to increase a more even distribution of doctors in rural areas. ${ }^{46}$ This can be seen as an important and feasible factor to consider when designing any interventions to increase the number of medical doctors in rural areas of LMICs. Training the students in rural settings adds to the rural interest of the student. Availability of training locations in low-income countries is an issue that also may need to be explored. While factors like communitybased education and rural training are being discussed, attention should also be paid to the reality that the health facility in rural areas of low-income countries lacks even the basic infrastructure. Training in rural health facilities may motivate the students to pursue careers in rural locations. However, countries may also need to invest in the development of rural health facilities.

A medical school-related impediment to rural practice is the high tuition fees paid at private medical schools. National policies that provide financial support for medical education in return for service in rural areas can influence students' choices towards rural practices. They voluntarily opt for the schemes in order to start their medical education. Short contracts could also work in favour of motivating rural practice. Taking into account country-specific relevant factors, policy interventions may be designed as outlined by the $\mathrm{WHO},{ }^{5}$ to increase medical doctors in rural areas through the motivation of the medical students.

The basic factors linked with physical development like infrastructure and health facilities are more reported as impediments to rural practice in the future from low-income countries compared with middleincome countries.

\section{Relationship between the factors}

All five categories of factors are linked with the income level of the country. There is most likely an interplay between the factors that contribute to the overall shortage of the health workforce in rural areas of LMICs. Addressing factors individually as well as looking across the factors is important. Strategies that address multiple influences would be useful. Rural background is the most commonly reported factor in this review and in some high-income countries, some preference has been given to rural students for medical school admission. ${ }^{47-49}$ Medical school factors that include consideration of student admission, curriculum geared towards rural areas and rural exposure during placement have been reported in the literature for high-income countries as important. ${ }^{23} 26$ 50-54 Although the literature we found on LMICs had only a limited focus on medical 
school factors, potentially developing strategies to create graduates who are more confident and committed to working in resource-limited rural areas could be helpful. A sequence of interventions from selective admission for students with a rural background, community-based medical education and clinical training in rural areas during undergraduate medical education is seen to increase rural practice motivation among medical students. ${ }^{26}$ Establishing medical schools in rural areas could be adopted by governments to potentially increase rural motivation among the medical students. ${ }^{55}$ The health facility factors appear to be an important influence in low-income countries, where the disparities between urban and rural facilities are greatest. Communities, medical schools and governments all need to work together to develop the health infrastructure and staffing of facilities in rural areas. High tuition fees in medical schools reported from low-income countries could be linked with the policy intervention of providing scholarships to medical students. This may address the obstacle of high tuition fees to support students from rural areas to attend medical school. A policy of financial aid to students during medical education has been used as a successful strategy in high-income countries. ${ }^{5657}$ These factors may need further investigation in terms of motivation to work in rural areas following graduation.

\section{Quality of included studies}

Since the available studies are either cross-sectional, mixed methods or qualitative, the studies included in this systematic review are of either low quality or very low quality as classified by the GRADE approach ${ }^{35}$ for observational studies. However, since these are the only studies that are found for review, the findings may still be valid to summarise the factors influencing medical students' motivation to practise in rural areas of LMICs. Intervention studies, cohort and case-control studies may have generated higher quality of evidence in this subject matter.

\section{Limitations of the study}

The search strategy to include only English language could have resulted in missing some relevant articles in other languages. The choice of key words and their combinations may have limited the search results to the identified studies in this review. Since only observational studies were found, there were no studies that were of moderate or high quality of evidence according to the GRADE approach.

\section{CONCLUSIONS}

The current review suggests that among the powerful motivators for rural practice following graduation is rural background. Selecting medical students from rural backgrounds seems an important area for low-income countries. Together, rural background and community- based medical education perhaps act to increase student exposure to the needs of rural communities and the personal benefits of rural practice. Low-income countries could also consider ensuring a minimum infrastructure of health facilities in rural areas in addition to addressing other important factors. An understanding of the factors influencing medical graduates in LMICs is, however, limited. Further identification of locally relevant factors may be useful to design country-specific interventions.

Acknowledgements The authors would like to acknowledge the resources and guidance received from the Royal Tropical Institute, Netherlands for writing this paper. The authors acknowledge the support received from Hellen Gelband and Dr Sarity Dodson to improve the English language in the paper.

Contributors SSB, PACZ, PKP and AJS all contributed to the conception of the study. SSB, PACZ and AJS analysed and interpreted the data of the work. Drafting of the manuscript and revising it critically for the important intellectual content was done by SSB and PACZ. Manuscript preparation, editing and finalising of the version to be published is the work of SSB, PACZ, PKP and AJS. All authors agree to be accountable for all aspects of the work related to the integrity of the work.

Funding This research received no specific grant from any funding agency in the public, commercial or not-for-profit sectors.

Competing interests None declared.

Provenance and peer review Not commissioned; externally peer reviewed.

Data sharing statement No additional data are available.

Open Access This is an Open Access article distributed in accordance with the Creative Commons Attribution Non Commercial (CC BY-NC 4.0) license, which permits others to distribute, remix, adapt, build upon this work noncommercially, and license their derivative works on different terms, provided the original work is properly cited and the use is non-commercial. See: http:// creativecommons.org/licenses/by-nc/4.0/

\section{REFERENCES}

1. World Health Organization. How to conduct a discrete choice experiment for health workforce recruitment and retention in remote and rural areas: a user guide with case studies. Geneva: World Health Organization. 2012.

2. WHO. World Health Report. Working together For health. Geneva, 2006.

3. Sousa A, Dal Poz MR, Boschi-Pinto C. Reducing inequities in neonatal mortality through adequate supply of health workers: evidence from Newborn Health in Brazil. PLOS ONE 2013;8:e74772.

4. Srinivasan CS, Zanello G, Shankar B. Rural-urban disparities in child nutrition in Bangladesh and Nepal. BMC Public Health 2013;13:581.

5. World Health Organization. Increasing access to health workers in remote and rural areas through improved retention global policy recommendations. World Health Organization. Geneva: World Health Organization, 2010:1-80.

6. Huntington I, Shrestha S, Reich NG, et al. Career intentions of medical students in the setting of Nepal's rapidly expanding private medical education system. Health Policy Plan 2012;27:417-28.

7. Ahmed SM, Majumdar MAA, Karim R, et al. Career choices among medical students in Bangladesh. Adv Med Educ Pract 2011;2:51-8.

8. Burch VC, McKinley D, van Wyk J, et al. Career intentions of medical students trained in six sub-Saharan African countries. Educ Health 2011;24:614.

9. Van Wyk J, Naidoo S, Esterhuizen T. Will graduating medical students prefer to practise in rural communities ? S Afr Fam Pract 2010;52:149-53.

10. Deressa W, Azazh A. Attitudes of undergraduate medical students of Addis Ababa University towards medical practice and migration, Ethiopia. BMC Med Educ 2012;12:68.

11. Diwan V, Minj C, Chhari N, et al. Indian medical students in public and private sector medical schools: are motivations and career 
aspirations different?-studies from Madhya Pradesh, India. BMC Med Educ 2013;13:127.

12. Harris MG, Gavel PH, Young JR. Factors influencing the choice of specialty of Australian medical graduates. Med J Aust 2005;183:295-300.

13. Dussault G, Franceschini MC. Not enough there, too many here: understanding geographical imbalances in the distribution of the health workforce. Hum Resour Health 2006;4:12.

14. Morrison J. Influences before and during medical school on career choices. Med Educ 2004;38:230-1.

15. Brooks RG, Walsh M, Mardon RE, et al. The roles of nature and nurture in the recruitment and retention of primary care physicians in rural areas: a review of the literature. Acad Med 2002;77:790-8.

16. Reid SJ, Couper ID, Volmink J. Educational factors that influence the urban-rural distribution of health professionals in South Africa: a case-control study. S Afr Med J 2011;101:29-33.

17. Franco LM, Bennett $S$, Kanfer R. Health sector reform and public sector health worker motivation: a conceptual framework. Soc Sci Med 2002;54:1255-66.

18. Lamichhane J. Dilemma of medical graduates in Nepal. J Nepal Health Res Counc 2010;8:116-19.

19. Eley DS. Postgraduates' perceptions of preparedness for work as a doctor and making future career decisions: support for rural, non-traditional medical schools. Educ Health Chang Learn Pract 2010;23:9.

20. Farmer J, Kenny A, McKinstry C, et al. A scoping review of the association between rural medical education and rural practice location. Hum Resour Health 2015;13:27.

21. Ross AJ. Working in rural areas-the experiences of Umthombo Youth Development Foundation graduates. Afr J Prim Health care Fam Med 2014;6:E1-7.

22. Ross A, MacGregor G, Campbell L. Review of the Umthombo Youth Development Foundation scholarship scheme, 1999-2013. Afr J Prim Health Care Fam Med 2015;7:1-6.

23. Barrett FA, Lipsky MS, Lutfiyya MN. The impact of rural training experiences on medical students: a critical review. Acad Med 2011;86:259-63.

24. Curran V, Rourke J. The role of medical education in the recruitment and retention of rural physicians. Med Teach 2004;26:265-72.

25. Crampton PES, McLachlan JC, Illing JC. A systematic literature review of undergraduate clinical placements in underserved areas. Med Educ 2013;47:969-78.

26. Hsueh W, Wilkinson T, Bills J. What evidence-based undergraduate interventions promote rural health? N Z Med J 2004;117:U1117.

27. Ranmuthugala G, Humphreys J, Solarsh B, et al. Where is the evidence that rural exposure increases uptake of rural medical practice? Aust J Rural Health 2007;15:285-8.

28. Bland CJ, Meurer LN, Maldonado G. Determinants of primary care specialty choice: a non-statistical meta-analysis of the literature. Acad Med 1995;70:620-41.

29. Lehmann U, Dieleman M, Martineau T. Staffing remote rural areas in middle- and low-income countries: a literature review of attraction and retention. BMC Health Serv Res 2008:8:19.

30. AusAID. The logical framework approach. Canberra. 2003.

31. Smith JD, Margolis SA, Ayton J, et al. Defining remote medical practice: a consensus viewpoint of medical practitioners working and teaching in remote practice. Med J Aust 2008;188:159-61.

32. Crandall M, Weber B. Defining rural Oregon: an exploration. Corvallis: Rural Studies Program, Oregon State University; 2005.

33. Pong RW, Pitblado JR. Don't take "geography" for granted! Some methodological issues in measuring geographic distribution of physicians. Can J Rural Med 2001;6:103-12.

34. Moher D, Liberati A, Tetzlaff J, et al. Preferred reporting items for systematic reviews and meta-analyses: the PRISMA statement. PLoS Med 2009;6:e1000097.

35. Cochrane. The GRADE approach. In: Higgins JP, Green S, eds. Cochrane Handbook for Systematic Reviews of Interventions. 5th edn. The Cochrane Collaboration, 2011:361-2.
36. World Bank. Country and Lending Groups I Data [Internet]. 2014. (cited 2014 Aug 3). http://data.worldbank.org/about/ country-and-lending-groups

37. Kaye DK, Mwanika A, Sekimpi P, et al. Perceptions of newly admitted undergraduate medical students on experiential training on community placements and working in rural areas of Uganda. BMC Med Educ 2010;10:47.

38. Arscott-Mills T, Kebaabetswe P, Tawana G, et al. Rural exposure during medical education and student preference for future practice location-a case of Botswana. Afr J Prim Health Care Fam Med 2016;8:a1039.

39. Nallala S, Swain S, Das S, et al. Why medical students do not like to join rural health service? An exploratory study in India. J Fam Community Med 2015;22:111-17.

40. Kruk ME, Johnson JC, Gyakobo M, et al. Rural practice preferences among medical students in Ghana: a discrete choice experiment Bull World Health Organ 2010;88:333-41.

41. Bailey N, Mandeville KL, Rhodes T, et al. Postgraduate career intentions of medical students and recent graduates in Malawi: a qualitative interview study. BMC Med Educ 2012;12:87.

42. Shankar PR, Thapa TP. Student perception about working in rural Nepal after graduation: a study among first- and second-year medical students. Hum Resour Health 2012;10:27.

43. Zimmerman M, Shakya R, Pokhrel BM. Medical students' characteristics as predictors of career practice location: retrospective cohort study tracking graduates of Nepal's first medical college. BM 2012;4826:1-10.

44. Ross AJ. Success of a scholarship scheme for rural students. S Afr Med J 2007:97:1087-90.

45. Kotha SR, Johnson JC, Galea S, et al. Lifecourse factors and likelihood of rural practice and emigration: a survey of Ghanaian medical students. Rural Remote Health 2012;12:1898.

46. Larkins S, Michielsen $\mathrm{K}$, Iputo J, et al. Impact of selection strategies on representation of underserved populations and intention to practise: international findings. Med Educ 2015;49:60-72.

47. Royston PJ, Mathieson K, Leafman J, et al. Medical student characteristics predictive of intent for rural practice. Rural Remote Health 2012;12:2107.

48. Pretorius RW, Milling DA, Mcguigan D. Influence of a rural background on a medical student's decision to specialize in family medicine. Rural Remote Health 2008;8:1-5.

49. Jones MP, Eley D, Lampe L, et al. Role of personality in medical students' initial intention to become rural doctors. Aust J Rural Health 2013;21:80-9.

50. Halaas G. The Rural Physician Associate Program: successful outcomes in primary care and rural practice. Rural Remote Health 2005;5:453.

51. Jones MP, Bushnell JA, Humphreys JS. Are rural placements positively associated with rural intentions in medical graduates? Med Educ 2014:48:405-16.

52. Eley DS, Synnott R, Baker PG, et al. A decade of Australian Rural Clinical School graduates-where are they and why? Rural Remote Health 2012;12:1937.

53. Clark TR, Freedman SB, Croft AJ, et al. Medical graduates becoming rural doctors: rural background versus extended rural placement. Med J Aust 2013;199:779-82.

54. Okayama M, Kajii E. Does community-based education increase students' motivation to practice community health care? A cross sectional study. BMC Med Educ 2011;11:19.

55. Longombe AO. Medical schools in rural areas-necessity or aberration? Rural Remote Health 2009;9:1131.

56. Rabinowitz HK, Diamond JJ, Markham FW, et al. Increasing the supply of rural family physicians: recent outcomes from Jefferson Medical College's Physician Shortage Area Program (PSAP). Acad Med 2011;86:264-9.

57. Matsumoto M, Inoue K, Kajii E. A contract-based training system for rural physicians: follow-up of Jichi medical. J Rural Health 2008;24:360-8. 